\title{
O CINEASTA SERTANEJO JOSAFÁ DUARTE: NARRATIVAS DE VIDA E OBRA NO CONTEXTO CONTEMPORÂNEO
}

- PAULO PASSOS DE OLIVEIRA

Universidade Federal de Goiás

RAIMUNDO MARTINS

Universidade Federal de Goiás

RESUMO Este artigo apresenta narrativas de vida e trabalho do produtor, roteirista e cineasta Josafá Ferreira Duarte, morador do distrito de Salgado dos Mendes, município de Forquilha, zona norte do Estado do Ceará. Analisa o seu contexto de produção, traçando vínculos com a pós-modernidade, a partir de rupturas de paradigmas que envolvem as viradas "cultural", "pictórica" e "linguística". Para este artigo foram realizadas duas entrevistas: a primeira, presencial, em agosto de 2013; a segunda, por telefone, em maio de 2016. Tomamos como referência quatro filmes realizados pelo cineasta e o blog no qual ele divulga seu trabalho. Partindo das entrevistas e dialogando com vários autores, refletimos acerca das narrativas de vida e obra de Josafá, colocando em perspectiva questões da contemporaneidade. Desprovido de recursos financeiros e instrumentais, sem formação técnica e teórica em cinema e distante dos grandes centros produtores de audiovisual, o trabalho de Josafá mostra a proliferação de signos e mudanças nos regimes de visualidade que, proporcionadas pela cultura e pelas novas tecnologias, alcançaram o sertão de Salgado dos Mendes, possibilitando o desenvolvimento do cinema popular.

Palavras-chave: Josafá Duarte. Pós-modernidade. Virada cultural. Virada pictórica. Virada linguística.

ABSTRACT THE FILMMAKER SERTANEJO JOSAFÁ DUARTE:

NARRATIVES OF LIFE AND WORK IN THE CONTEMPORARY CONTEXT

This article presents narratives of life and work of the producer, writer and filmmaker Josafá Ferreira Duarte, resident of Salgado dos Mendes, district of Forquilha, a little town on the northern part of the Ceará state. It analyses his production context tracing links with 
postmodernism based on paradigms breaks involving the "cultural", the "pictorial" and "language" turns. For this article two interviews were carried out: the first, personally, took place in August of 2013; the second, by telephone, in May 2016. We took as references four films made by the filmmaker and the blog in which he reveals his work. Using the interviews and dialoguing with several authors, we reflect on the narratives context of life and work of Josafá, putting in perspective contemporary issues. Devoid of financial and instrumental resources, without technical and theoretical training in cinema, and distant from the large audiovisual production centers, Josafá's work shows the proliferation of signs and changes in the regimes of visualities that, provided by culture and new technologies, reached the backlands of Salgado dos Mendes, making possible the development of popular cinema.

Keywords: Josafá Duarte. Postmodernism. Cultural turn. Pictorial turn. Language turn.

\section{RESUMEN EL CINEASTA CAMPONES JOSAFÁ DUARTE: NARRATIVAS DE VIDA Y OBRA EN EL CONTEXTO CONTEMPORÁNEO}

Este artículo presenta narrativas de vida y obra del productor, escritor y director de cine Josafá Ferreira Duarte, que habita la localidad de Salgado dos Mendes, provincia de Forquilha, en la parte norte del estado de Ceará. Analiza su contexto de producción trazando vínculos con la posmodernidad a partir de cambios de paradigmas envolviendo los giros "cultural", "pictórico" y "lingüístico". Para este artículo se realizaron dos entrevistas: la primera, presencial, en agosto de 2013; la segunda, por teléfono, en mayo de 2016. Hemos tomado como referencias cuatro películas realizadas por el cineasta y el blog que divulga su trabajo. Utilizando las entrevistas y dialogando con varios autores, reflexionamos acerca de las narrativas de vida y obra de Josafá, colocando en perspectiva cuestiones contemporáneos. Desproveído de recursos financieros e instrumentales, sin formación técnica y teórica en el cine y distante de los principales centros de producción audiovisual, el trabajo de Josafá muestra la proliferación de signos y los cambios en los regímenes de visualidades que, proporcionados por la cultura y las nuevas tecnologías, llegaron al interior de Salgado dos Mendes, posibilitando el desarrollo del cine popular.

Palabras clave: Josafá Duarte. Posmodernidad. Giro cultural. Giro pictórico. Giro lingüístico. 


\section{Josafá Duarte: uma biografia em construção...}

Josafá Ferreira Duarte é morador do distrito de Salgado dos Mendes, onde vivem cerca de 500 pessoas, localidade do município de Forquilha, zona norte do Estado do Ceará. Ele pertence a um grupo de realizadores de cinema oriundos de regiões que não possuem os aparelhos culturais legitimados socialmente: galerias de arte, bibliotecas, museus e salas de cinema. O sujeito deste artigo não recebeu educação formal e institucionalizada no campo audiovisual, ou mesmo em outras artes ou em cultura visual. Entretanto, ao contrário do que supõe o determinismo social fatalista - e perigoso -, ele ingressou, no ano de 2012, em um curso superior de Pedagogia realizado em módulos, que concluiu em julho de 2016.

o grupo de fazedores de filme cresce em todo o Brasil: Manoel Loreno (Mantenópolis ES), Martins Muniz, Hugo Caiapônia (ambos de Goiânia - GO), e José de Oliveira, mais conhecido como Zé Pintor (São Carlos - SP) são apenas quatro exemplos dentre vários outros. Estes cineastas foram antecedidos por Afonso Brazza (Gama - DF - 1955-2003), Simião Martiniano (Recife - PE - 1932-2015) e, provavelmente, vários que não chegaram a ter minimamente a notoriedade dos cineastas aqui citados. A associação entre eles não se circunscreve a academias, sindicatos ou agremiações, mas pertence a uma costura simbólica realizada pelo fazer cinematográfico cotidiano.

0 ambiente deste artigo:

[...] reporta-se ao trabalho de cidadãos comuns que, movidos a paixão pelo cinema, dedicam seus esforços para assegurar, não só para si, como também para suas comunidades, [...] a aventura de contar suas próprias histórias, ainda que em condições precárias, e à revelia dos sempre onerosos orçamentos das produções cinematográficas disponiveis no mercado do entretenimento. [...] Tomam parte, sim, da corveia anônima, como cidadãos que, desconhecendo as adversidades, atuam em seus próprios contextos, construindo suas próprias narrativas, entre tessituras, diálogos e negociações sempre dinâmicas, entrecortadas por dificuldades e conflitos, sonhos e paixões. (MARTINS, 2013, p. 13)

Afonso Brazza ganhava a vida como bombeiro militar. Simião Martiniano era camelô. Josafá vive como agricultor. Pelas razões apresentadas, a história de Josafá merece ser contada.

Aos 56 anos, Josafá Duarte finalizou 23 filmes de ficção entre curtas, médias e longasmetragens. Seu processo de realização cinematográfica começou em 2006. As produções deste fazedor de filmes possuem uma particularidade: a motivação política.

O cineasta de Salgado dos Mendes definese como alguém que gosta da terra. É filiado ao Sindicato dos Trabalhadores Rurais de ForquiIha e já atuou no Movimento dos Trabalhadores Rurais sem Terra (MST). Foi através deste grupo que Josafá participou de ocupações de latifúndios improdutivos em Pentecoste, na região do Médio Curu, a $89 \mathrm{~km}$ da capital Fortaleza, no Ceará, entre o final do século XX e início do XXI. Josafá relata que foi informado por funcionários do Instituto Nacional de Colonização e Reforma Agrária (Incra) que estava ameaçado de morte por fazendeiros da região. Depois de cinco anos vinculado a movimentos sociais e, em especial, ao MST, decidiu que era hora de parar. O grupo já havia conseguido assentar 40 famílias na fazenda Lagoa Grande, em Pentecoste. Nesse período, ficou sob proteção da Polícia Federal por 10 dias. Foi quando decidiu retornar a Forquilha, distrito de Salgado dos Mendes. Era o ano de 2002.

Pronto: agora vou tentar me aquietar. Aí, a primeira coisa que eu fiz foi criar um jornal. 0 jornal Sociedade Salgadense. Vou começar, então, a denunciar o que eu tava vendo de errado, né?! Um jornal independente. Aí eu comecei a fazer o cinema, que eu vi que era algo que podia atingir mais e ir mais longe. Eu pensei que ia 
me aposentar dessa vida de militância, né, mas não: eu vi que tinha outro capítulo da história da minha vida que era esse, lutar pela minha própria comunidade. (OLIVEIRA, 2013)

Servido de uma câmera emprestada, o agricultor tornava-se cineasta. A necessidade de fazer era superior ao saber fazer. Intuitivamente, ele supunha que o cinema teria um alcance maior em uma sociedade com baixo grau de escolaridade formal, portanto, ver um filme causaria maior efeito do que ler uma notícia. Assim nasceu o primeiro filme de Josafá Ferreira Duarte: "A história de um galo assado" (DUARTE, 2006).

A própria comunidade torna-se responsável pela criação do processo cinematográfico. Envolve-se na produção, maquiagem, costura figurinos, prepara e serve o lanche, atua, junta elementos materiais para compor a arte e os cenários, labuta na parte técnica. Assim surgiu o coletivo Cinecordel, nome que homenageia a literatura popular presente no interior de algumas partes do Nordeste do Brasil. O cineasta Josafá homenageava também seu pai, cordelista. Assim se fortalecem laços sociais dentro de um grupo.

O grupo é da própria comunidade. É tudo de agricultores, analfabetos de pai e mãe, pode se dizer assim, né?! Pessoas que não sabem nem escrever o nome, botam é o dedo. Mas eu me senti à vontade porque é o meu povo, é a minha gente, né?! Então, eu sou também trabalhador braçal e estava também na minha comunidade e eu me sentia à vontade. Então, eu dizia: vamos fazer o filme, vamos filmar que história? Pronto... (OLIVEIRA, 2013)

Com o passar do tempo, depois de cinco filmes, Josafá foi aprendendo de tudo um pouco: manusear câmeras, usar um computador que lhe foi presenteado, e fez alguns cursos ligados ao universo audiovisual na sede de Forquilha e em Sobral, município vizinho e cidade polo da região. Mas a apropriação das ferramentas e o uso das diferentes tecnologias necessárias para a execução de trabalhos audiovisuais são, ainda hoje, uma provação para Josafá. Para vencer os desafios, o produtor se cerca de jovens que possuem expertise técnica suficiente para manipular câmeras e computadores.

Atualmente, o diretor forquilhense realiza entre três e quatro produções por ano. Os filmes costumam ser lançados de forma festiva em algum espaço público na comunidade, que pode ser a parede de uma igreja ou a única quadra poliesportiva do distrito. Depois, são feitas cópias vendidas a preço quase de custo. Entretanto, com a possibilidade de fabricação de cópias a partir de DVDs, as produções do cineasta de Salgado dos Mendes acabam sendo multiplicadas e vendidas por camelôs. Mas não são negociadas apenas por vendedores informais de Forquilha. Os filmes de Josafá, atualmente, podem ser encontrados em bancas de Sobral, na capital Fortaleza, e em vários estados da Federação, como Tocantins, Maranhão, Piauí e Pernambuco, somente para citar alguns. O filho do produtor de cinema, que é caminhoneiro, encontrou um DVD de um filme de Josafá disponivel para venda em uma banca de jornal de Pernambuco. Ele se sente incomodado com a pirataria?

Eu fico assim feliz em saber que em outro Estado bem distante aqui da minha comunidade as pessoas estão assistindo e estão copiando. Né?! Isso é maravilhoso. Isso incentiva eu a continuar fazendo as minhas produçõezinhas caseiras, né, com o objetivo de formar [...] cidadões (sic.) mas mais conscientes em termos da politicagem, da política... (OLIVEIRA, 2013)

Além disso, a multiplicação das cópias permite a interiorização de elementos culturais da região. As produções do cineasta de Salgado dos Mendes, majoritariamente balizadas pelo gênero comédia, têm histórias inspiradas em personagens e situações típicas do cotidiano daquela comunidade. 
Óia, meus filmes sempre têm mostrado a cultura: do trabalhador rural, do homem que trabaIha na roça, da mulher que faz chapéu, do reisado, do cantador, entendeu, do caba que compra e não paga, né, do caba que é traído pela mulher, entendeu, os apelidos, essas coisas da minha terra. Então, a minha história está ligada à história deles. (OLIVEIRA, 2013)

A obra de Josafá Duarte ganha capilaridade, visibilidade e borrifa informações da cultura de Forquilha, especialmente de Salgado dos Mendes, em direção ao Brasil. Enquanto isso, o próprio fazedor de filmes investe na formação de crianças de sua comunidade, visando à continuidade da sua atividade e à formação de público, oferecendo oficinas e exibindo seus filmes.

Josafá Duarte precedeu e estimulou o aparecimento de outros criadores do cinema forquilhense como Ronaldo Roger, Paulo Talentos e Aureliano Shekinah. Essa repercussão e divulgação levaram os cineastas de Forquilha, liderados por Josafá, a concederem entrevista para uma equipe de jornalismo da TV Cidade afiliada da Record no Ceará - no ano de 2013.

O grupo de amigos realizou um festival autônomo de cinema no ano de 2014: I Festival de Cinema de Forquilha, no período de 14 a 16 de fevereiro. Nessa edição, o precursor do cinema no município foi agraciado com os troféus de Melhor Filme e Melhor Diretor. Dos representantes do poder público, compareceu o secretário de Cultura, que apoiou o evento.

o poder público municipal levou quase uma década para reconhecer o trabalho do coletivo Cinecordel. Com o sucesso da primeira edição do festival, o prefeito de Forquilha, secretários, deputado federal e estaduais compareceram à festa de premiação na segunda edição do festival, em 2015, transformando a festa em palanque, em que o whisky era servido exclusivamente para autoridades políticas e para os irmãos da maçonaria. Nessa noite, em vários discursos, foi destacada a "capaci- dade inata" de realização de filmes do povo forquilhense. Josafá conquistou o prêmio de Melhor Diretor pelo curta-metragem "Cadê meu zóculos" (DUARTE, 2015), que também recebeu os prêmios de Melhor Ator, concedido a José Gustavo, interpretando o prefeito Pedro Sola, e de Melhor Atriz, para Marliza Duarte, vivendo Rosa do João de Sousa.

O poder público foi obrigado a reconhecer o trabalho desempenhado pelo agricultor de Salgado dos Mendes, e procurou obter visibilidade com ele. Mas Josafá conseguiu contrapartidas. Agora, além de produtor e realizador, à frente do coletivo Cinecordel, e com o apoio da Secretaria da Cultura do Estado do Ceará, ele comanda um cineclube que exibe filmes em localidades do interior de Forquilha.

“Cadê meu zóculos" (DUARTE, 2015) representou outros voos para o cinema forquilhense. 0 equipamento, emprestado pelo cineasta Rosemberg Cariry (Corisco \& Dadá, 1996), permitiu melhor acabamento e finalização ao filme de Josafá. O curta foi agraciado com o prêmio do júri popular do V Festival Brasileiro do Cinema Digital, em Jijoca de Jericoacoara, no Ceará, o primeiro prêmio de porte nacional para um filme realizado em Forquilha. Este filme ganhou novas imagens, virou longa-metragem e foi exibido pela primeira vez, em 2016, na televisão aberta - TV Diário, canal do grupo Diário do Nordeste, disponível no Ceará. Além desta produção, a mesma emissora levou ao ar "O homem que queria enganar a morte" (DUARTE, 2014), em um programa chamado Diário do Cinema.

Atualmente, parte do trabalho de Josafá pode ser vista no blog Forquilha Cinecordel, bem como no YouTube. Sobre o YouTube, cabe narrar uma curiosidade. Em entrevista feita no mês de maio de 2016, por telefone, a esposa de Josafá, Noélia Duarte, interrompeu nossa conversa para informar que o canal via internet pagou a Josafá 100 dólares convertidos em reais 
depois que "Por debaixo dos panos" (DUARTE, 2010) - que os camelôs do Ceará rebatizaram com o título "Zé das Cachorras" - atingiu mais de 100 mil visualizações. Josafá não havia lembrado de contar a novidade (OLIVEIRA, 2016a).

O YouTube se tornou, então, uma fonte forte de divulgação do trabalho dos cineastas populares. Agora, em 2016, este canal assume um importante papel de exposição de novos trabalhos de Josafá. Ainda durante a conversa por telefone, sem adiantar maiores detalhes, o cineasta de Salgado dos Mendes informou que havia idealizado e começara a gravar uma série específica com cinco episódios para o YouTube (OLIVEIRA, 2016a).

Em entrevista concedida por Josafá em 2013, que não está publicada, há uma passagem emblemática: "Eu quero que Forquilha se transforme num polo de cinema. Eu quero transformar na capital do cinema popular nacional. Então, hoje eu já tenho esse desafio" (OLIVEIRA, 2013). Atualmente, em folhetos de propaganda da Prefeitura Municipal de ForquiIha, pode ser lido: "Forquilha, capital nordestina do Cinema Popular".

\section{Josafá Duarte: a pós-}

\section{modernidade e o contexto das} viradas cultural, pictórica e linguística

0 trabalho como fazedor de cinema efetivado por Josafá Duarte localiza-se entre o final do século XX e início do XXI. O barateamento do custo do equipamento básico de gravação e edição de vídeos - vídeocâmaras, computadores com programas de edição de imagens - permitiu que interessados na produção audiovisual pudessem contar suas histórias independentemente do conhecimento formal do processo de realização de filmes. Para Raimundo Martins (2015, p. 19), "a criação e disseminação da imagem em movimento oferece ao pú- blico a possibilidade de conjugar 'percepção crítica' e 'prazer estético', contrariando os cânones de uma prática erudita e desmistificando o rito da contemplação como uma fruição individualizada".

Dobers e Strannegard, referenciados por Martins (2015), nos dizem que o prazer estético proporcionado pelo mundo icônico na contemporaneidade permite a introdução por parte da estética de significados nos objetos transformando-os em conceitos que mobilizam os estilos de vida e criam disposições corporais.

É possível afirmar que, intuitivamente, o cineasta forquilhense - bem como outros fazedores de cinema - tenha encontrado no cinema as qualidades de fruição que considerava necessárias para a transmissão de suas ideias. Para além do jornal Sociedade Salgadense, que continua sendo publicado, o cinema oferece condições para o espectador ver casos criados em locais que ele reconhece e situações com as quais está familiarizado. 0 morador de Salgado dos Mendes, de Forquilha, e do interior do Ceará, reconhece-se nas paisagens, nos sotaques, na arquitetura, nos adereços, bem como nos costumes e práticas revelados em tom farsesco e tingidos pela comédia, aproximando a sua realidade daquela apresentada nos filmes. Para aqueles que veem os filmes de Josafá e não participam do universo criado pelas tramas, o envolvimento com a história é possivel devido ao reconhecimento de uma linguagem cinematográfica convencional, pelo que é típico, e pela graça quase circense.

O universo do cineasta de Forquilha está imerso nos seus filmes. Este universo diz respeito ao fenômeno da cultura, que deve ser compreendida dentro de sua dinamicidade e plasticidade.

Raimundo Martins (2015, p. 20) explica que “a pluralização da palavra 'cultura' intensificou a dimensão social dessas transformações que passaram a ser conhecidas como um fenôme- 
no", e cita Peter Burke para definir o contexto do que é definido como "virada cultural" (cultural turn):

[...] uma 'virada cultural' mais ampla em termos de ciência política, geografia, economia, psicologia, antropologia e 'estudos culturais'. Houve um deslocamento nessas disciplinas, pelo menos entre uma minoria de acadêmicos, que passaram da suposição de uma realidade imutável (a teoria da escolha racional em eleições ou em atos de consumo, por exemplo) para um interesse nos valores defendidos por grupos particulares em locais e períodos específicos. (BURKE apud MARTINS, 2015, p. 8)

Pensar a cultura, aqui, é considerar a ação dos sujeitos de uma dada sociedade, bem como suscitar uma reflexão sobre aqueles que pensam o fenômeno da cultura. O sujeito passa a ser produzido no devir de uma cultura que passa a ser afetada por inúmeras conjunções. Dessa forma, em certa medida, os sujeitos passam a ser vistos como produtos da cultura. No âmbito da cultura visual, esta virada explicita que a arte é mais do que um inventário de obras e "gênios criadores". A proliferação de imagens possibilitou a construção e a revisão da ideologia e da identidade dos sujeitos contemporâneos.

O termo cultura, segundo Raymond Williams (1965), descreve um modo de vida integral por onde se expressam certos significados e valores presentes no conjunto de instituições da vida social. A cultura não é imanente nem está limitada às esferas autônomas da arte ou da educação, mas possui uma existência material cujas formas devem ser reinventadas por todos aqueles grupos excluídos tradicionalmente das instituições culturais - por classe, gênero, raça ou orientação sexual - comprometidos com a tarefa de imaginar as formas de participação adequadas para sustentar uma cultura comum e redistribuir o valor cultural. Esta luta fica redefinida como luta cultural e, assim, a cultura não pode ser entendida - como pretendia o marxismo ortodoxo - nos termos de um efeito ideológico supraestrutural (LUNA, 2010).

A epistemologia e as análises do campo das manifestações visuais passam a ser relativizadas e colocadas em contextos específicos, considerando contingências sociais, políticas e econômicas. Esta virada permitiu o surgimento do próprio termo "cultura visual", que quebra a dicotomia razão/emoção. Neste sentido, o local e as contingências permitem especial configuração nas produções dos sujeitos, imbricando imagem/vida, rompendo com o discurso autônomo da obra de arte.

A experiência que o sujeito contemporâneo estabelece com a imagem o leva a refletir sobre o mundo fragmentado. 0 devir sujeito permite pensar o mundo como devir mundo, portanto, mundo em constante construção. Isso tornouse possivel graças a outra importante virada: a "virada pictórica" (pictorial turn).

Segundo Imanol Aguirre, Walter Benjamim antecipou a ideia de que a "virada pictórica" compõe a maneira de relação estabelecida entre o político e o estético:

Ao estabelecer uma relação entre a multiplicação das imagens e suas consequências na vida pública, Benjamim chamou a atenção sobre outro dos fenômenos em que claramente se concentraram os estudos de cultura visual e seu correlato educativo: os efeitos que este regime de visualidade tem na estetização da vida. (AGUIRRE, 2011, p. 79)

Dessa forma, pode-se afirmar que o cinema nasce político. A relação entre cinema e política pode ser compreendida sob muitos aspectos, mas aqui esta aproximação pode ser feita como aquela em que os enunciadores - políticos e cineastas - falam às massas em uma perspectiva que envolve poder, linguagem, criticidade e ética. Josafá age politicamente ao tratar de política. Portanto, seria exagerado 
afirmar que o cinema feito por Josafá é metapolítico?

Josafá Duarte faz cinema em consonância com as condições e possibilidades do momento histórico em que vive. Realiza narrativas fiImicas com base naquilo que the foi dado ver. O cineasta forquilhense está inserido em um momento denominado por William Mitchell (2005) como virada pictórica, período em que as artes invadem a vida cotidiana, há a ruptura aurática das obras de arte - como preconizado por Benjamin, em seu artigo referência: “ $A$ obra de arte na época da sua reprodutibilidade técnica" (BENJAMIN, 1990) - e uma proliferação incessante de signos através de tecnologias de informação e comunicação. Estas características fazem parte do regime de visualidades da contemporaneidade que vários autores nomeiam pós-modernidade.

Efland, Freedman e Sthur (2003) esclarecem que o conceito de pós-modernidade evolui na mesma velocidade que outros conceitos relativamente modernos. Uma explicação possivel encontra-se no fato de que ainda não há um afastamento histórico de nossa experiência contemporânea, de tal forma que as cisões e mudanças na contemporaniedade criam um conceito fluido, no sentido que nos é apresentado por Bauman (2000). Para Jameson (1996), o momento pós-moderno teria começado na segunda metade do século XX, com a radicalização da expressão monetária que remete a trocas flutuantes e modulações cifradas e imateriais.

É possivel designar o ambiente e os fenômenos sociológicos que tornam possiveis a troca artística. Nesse sentido, trata-se de um ceticismo tocante às concepções modernas de progresso, de hierarquização do conhecimento e da objetividade em um mundo fragmentado e plural.

A experiência subjetiva do homem da modernidade foi se intensificando com o desen- volvimento tecnológico dos meios de comunicação de massa audiovisuais, como o próprio cinema, o rádio, a televisão e, mais recentemente, as mídias digitais. Esses dispositivos que vêm sendo desenvolvidos a partir da segunda metade do século XIX tornaram o mundo mais próximo.

A cultura pós-moderna sobrevive na necessidade da imagem e no desejo em função do objeto. A imagem, ao contrário da linguagem - estruturada por regras sistemáticas -, fundamenta-se na memória perceptual inconsciente. Portanto, esta característica pós-moderna é também uma característica da sociedade de consumo.

Em entrevista realizada em 2013, Josafá titubeia quando questionado sobre os filmes que o inspiraram.

[...] tem uns filmes que eu gosto, uns seriado que eu assisti quando era pequeno, que era menino quando assistia, mas me inspirar num filme, em si, eu acho que eu desconheço. [...] Mas dos filmes que eu adoro, assisti aquele, é... "Casablanca" [Michael Curtiz, 1945]! Foi um clássico que eu assisti mais de 50 vezes e eu gosto de assistir pela história, pela qualidade do filme, pela fotografia, né, e eu também gosto, assim, de filme de guerra... É, é um filme em preto e branco que eu assisti mais de 50 vezes mas eu gosto, eu gostei da história, muito bonito o filme, né?! [...] Eu gosto muito de comédia, né?! Eu gosto do filme "O auto da Compadecida" [Guel Arraes, 1999], né?! (OLIVEIRA, 2013)

A promessa política da arte está em sua desagregação, na oposição entre o "sensorium" da arte e a "estetização da vida cotidiana". A política estética autonomista considera que "a grande arte" testemunha o irrepresentável, o lugar do "outro" que conduz ao que Aguirre (2011) chama de formas de estetização mercantil da vida.

Olhar a "estetização da vida cotidiana", e, mais além, a "estetização da cultura", permite compreender o novo regime das visualidades e da sensibilidade adotado na pós-moderni- 
dade. No texto de Aguirre (2011), a estetização da vida cotidiana aparece em alguns momentos como um termo dado. Michael Featherstone, no livro "Cultura de consumo e pós-modernismo" (1995), discute em capítulo específico a estetização da vida cotidiana na modernidade e na pós-modernidade. 0 tema também é discutido por Jameson (1996), Baudrillard (1991), Kroker e Cook (1987) e Crary (1984), entre outros autores.

Featherstone (1995) afirma que é possivel pensar a estetização da vida cotidiana em três sentidos:

1. Durante o período da modernidade, nas subculturas que promoveram os movimentos dadaísta, surrealista e da vanguarda histórica na I Guerra Mundial e na década de 20 do século passado, procurando apagar as fronteiras entre arte e vida cotidiana. Desde a década de 60 , a arte pós-moderna, com sua reação contra a institucionalização do modernismo, apoia-se nessa estratégia.

2. A estetização da vida cotidiana pode designar o projeto de transformar a vida em obra de arte. Tal projeto teria começado no grupo Bloomsbury, na virada do século $X X$, e foi compartilhado por Oscar Wilde, no final do século XIX. Rorty (apud SHUSTERMAN, 1988) procura alargar novos gostos, sensações e possibilidades. Foucault (1984) menciona Baudelaire, que aprova o "dândi" que faz de seu corpo, sentimentos e sensações, uma obra de arte, posteriormente revelado no que autores chamam "estilo de vida". Uma vida que se constrói no prazer estético, associada ao consumo de massa e à eleição de formas de viver.

3. Estetização da vida cotidiana designa o fluxo de signos e imagens que saturam a vida pós-moderna. Para Adorno
(1985), apropriando-se de conceitos marxianos, 1 o aumento do valor de troca não apenas suprime o valor de uso como permitiu à mercadoria um valor secundário, que Baudrillard (1995) nomeia "valor-signo". A manipulação comercial das imagens, mediada pela publicidade, no ambiente midiático, determina a reativação dos desejos por meio das imagens. Atualmente, este terceiro aspecto é fundamental para compreendermos a imagem inserida no ambiente da cultura.

A discussão foi intensificada com argumentos a favor ou contra a integração entre arte e vida cotidiana. Ao tratarmos especificamente da cultura visual, vamos além dessa discussão, no sentido de que não nos interessam as formas de arte per se, mas os objetos da visualidade que transcendem as artes visuais. A estetização da vida cotidiana transcende a transformação da vida em obra de arte, mas encara a vida como regime estético.

É no seio das transformações da imagem contemporânea que pode ser pensada esta estetização da vida cotidiana. Graças à proliferação de imagens, e da possibilidade de criá-las, Josafá produz seu cinema. Neste processo de posse de tecnologias de gravação de imagens e de seu tratamento, bem como de apropriação da narrativa cinematográfica, Josafá inventa o cinema em Salgado dos Mendes.

A produção cinematográfica de Josafá Duarte está articulada ao que Aguirre define como outra importante virada que permite analisar o contexto da imagem contemporânea: a virada linguística (language turn) (AGUIRRE, 2011, p. 80).

1 Marxiano refere-se aos estudos feitos diretamente dos textos de Karl Marx, sobremaneira "O Capital", para compreender as conjunturas do capitalismo. Difere-se de marxismo, que reúne todos os movimentos de natureza social, política, cultural etc., de Marx e de outros autores que construíram suas teorias a partir de leituras dele. 
Para entender a virada linguística, é interessante definir e localizar o que se compreende como linguagem cinematográfica:

A linguagem no cinema não é formalizada. 'É claro que o cinema não é uma linguagem, mas gera seus significados por meio de sistemas (cinematografia, edição de som e assim por diante) que funcionam como linguagens' (TURNER, 1997). O cinema pode ser compreendido em primeira instância como comunicação; um segundo passo necessário é colocar este processo de comunicação dentro de um sistema maior gerador de significados: a própria cultura.

Os teóricos dos estudos culturais, fazendo especial referência à semiótica, 'argumentam que a linguagem é o principal mecanismo pelo qual a cultura produz e reproduz os significados sociais' (TURNER, 1997). Linguagem é aquela que vai além da língua verbal ou escrita. Mais do que isso, a cultura traz consigo um conjunto de valores do mundo fisico e social.

[Em suma,] O cinema também possui um conjunto de códigos e convenções edificados ao longo da história para que seja construído o sentido por parte do espectador, através de um acordo tácito que denota e permite a conotação do mundo. (OLIVEIRA, 2016b)²

Aguirre (2011) nos lembra que as visualidades não nos remetem apenas à percepção da linguagem, mas às suas formas de leitura. Nesta perspectiva, o mundo aparece como sistema de signos no qual há espaço para questões relativas aos significados e às narrativas. Através da "leitura das imagens" é possivel tomar consciência do poder da cultura visual e dos mecanismos de dominação postos em jogo. 0 cinema, enquanto arte narrativa, é portador de signos circunscritos a um campo estético e ao cotidiano.

2 O artigo "Josafá Duarte e o cinema autodidata" foi apresentado no V Colóquio Internacional Educación y Visualidad: investigaciones pedagógicas em contextos híper-visuales, realizado em Montevidéu (Uruguai), promovido pelo Instituto Escuela Nacional de Bellas Artes - Universidad de la República - Núcleo de Investigación en Cultura Visual, Educación y Construcción de Identidad, que ocorreu entre 09 e 11 de maio de 2016.

\section{Conclusão}

Oriundo de um interior do Brasil distante dos grandes centros, Josafá Duarte é alguém que se relaciona com as imagens de sua época a partir das condições sociais em que vive. Este processo se constitui em dupla instância. Em primeira via, Josafá teve acesso a imagens cinematográficas a partir da TV e das poucas vezes que foi ao cinema. Posteriormente, aparelhos de reprodução (videocassetes e reprodutores de DVD) permitiram o ato de ver filmes. Ver imagens cinematográficas é fundamental para se relacionar com elas, para desenvolver afetos e, enfim, apropriar-se da linguagem cinematográfica, quando é o caso. Em outra via, o barateamento do custo e a disponibilidade de ferramentas de registro de imagens (e som) em movimento, sua posterior edição, e a reprodução em mídias e na Internet permitiram ao cineasta de Forquilha a realização e a difusão de sua obra.

A militância política na vida de Josafá estendeu-se à militância no cinema. Esta forma de manifestação nasce em um novo contexto de visualidade que possibilita o desenvolvimento crítico a partir da experiência estética. Na pós-modernidade, o realizador de Salgado dos Mendes participa de um contexto cultural em que a imagem ganha aptidão para viajar insere-se na cultura em um contexto de troca - e se torna um capital financeiro (como fica evidente através da indústria cinematográfica hegemônica dos Estados Unidos). $\mathrm{Na}$ era da cultura de massa, o espaço da alta cultura e da cultura popular é relativizado pela apropriação promovida pelo mercado que, neste caso, permite o conhecimento acerca da diversidade de formas de narrativas filmicas.

Mas é na difusão proporcionada por imagens viajantes e pelo mercado dominante que surgem as fissuras, a resistência, o cinema político. É na apropriação e na ressignificação da linguagem inventada por Hollywood que o ci- 
nema de Josafá se estabelece com elementos culturais locais. É a partir daí que seu cinema se expande e se globaliza em mídias de DVD pirata e em canais do YouTube. É na própria arena da cultura em que a luta de Josafá se estabelece na disputa por significados (MIRZOEFF, 2011).

Considerar este contexto permite-nos chegar à conclusão de que alguém no interior de um país desigual como o Brasil, que vive longe dos centros difusores, desprovido de uma realidade material abastada, sem equipamentos culturais legitimados pelos cânones oficiais livrarias, bibliotecas, museus, galerias de arte, cinematecas - também está inserido no contexto da virada cultural à qual Burke e Martins se referem (2015).

A virada cultural é indissociável da quebra de outro importante paradigma da pós-modernidade: a virada pictórica. Na concepção de Mitchell (2005), a mudança nos regimes de visualidade relaciona a proliferação de signos visuais ao contexto da vida de seus produtores e daqueles que os veem.

\section{Referências}

ADORNO, Theodor; HORKHEIMER, Max. Dialética do esclarecimento: fragmentos filosóficos. Rio de Janeiro: Jorge Zahar Editor, 1985.

AGUIRRE, Imanol. Cultura Visual, Política da Estética e Educação Emancipadora. In: MARTINS, Raimundo; TOURINHO, Irene. (Orgs.). Educação da cultura visual: conceitos e contextos. Santa Maria: Editora UFSM, 2011. p. 69-111.

BAUDRILLARD, Jean. Para uma crítica da economia política dos signos. São Paulo: Martins Fontes, 1995.

Simulacros e simulação. Lisboa (Portugal): Relógio D’Água, 1991.

BAUMAN, Zigmunt. Modernidade líquida. Rio de Janeiro: Jorge Zahar Editor, 2000.

BENJAMIN, Walter. A obra de arte na era de sua re-
As imagens transcendem as características intrínsecas ao campo das artes, rompendo com o interesse exclusivamente estético devotado a elas, apontando para outros caminhos, imbricados na direção da cultura. Agora, a própria vida estetiza-se a partir das imagens. Neste sentido, problematizamos o ato de ver e de produzir visualidades. Não se trata exclusivamente de subordinar as produções visuais - e o universo "visto" por Josafá - ao campo da cultura, mas de compreender como estão aninhadas - em um sentido proposto por Mitchell (2009) - as referências afetivas, linguísticas e cinematográficas deste cineasta ao contexto estudado pela cultura visual.

Em todo o contexto que relaciona a produção de imagens e cultura, o mundo aparece como um texto a ser interpretado, compreendido e difundido, em uma virada linguística. A linguagem do cinema - esta mídia "impura", para além da mídia visual - surge como algo subjacente (MITCHELL, 2009). Assim, o cinema renasce como campo de possibilidade e de luta política.

produtibilidade técnica. In: LIMA, Luiz Costa. (Org.). Teoria da cultura de massa. São Paulo: Paz e Terra, 1990. p. 209-240.

CRARY, Jonathan. The eclipse of the espectacle. In: WALLIS, Brian. Art after Modernism: retihnking representation. NY (EUA): New Museum Press, 1984. p. 283-294.

EFLAND, Arthur; FREEDMAN, Kerry; STHUR, Patricia. Teoría posmoderna: cambiar concepciones del arte, la cultura y la educación. In: La educa-

ción en el arte posmoderno. Barcelona (Espanha): Paidós, 2003. p. 39-92.

FEATHERSTONE, Michael. Capítulo 5. A estetização da vida cotidiana. In:

Cultura de consumo e pós-modernismo. São Paulo: Studio Nobel, 1995. p. 97-117. 
FOUCAULT, Michel. O que é o Iluminismo? In: ESCOBAR, Carlos Henrique. (Org.). Michel Foucault (19261984): o Dossier - últimas entrevistas. Rio de Janeiro: Taurus, 1984. p. 103-112.

JAMESON, Fredric. Pós-modernismo: a lógica cultural do capitalismo tardio. São Paulo: Ática, 1996.

KROKER, Arthur; COOKER, David. The post-modern scene: excremental culture \& hyper aesthetics. Nova York (EUA): St. Martin Press, 1987.

LUNA, Sergio. La critica de la cultura después de la cultura. Estudios Visuales 7, Centro de Documentación y Estudios Avanzados de Arte Contemporáneo, Murcia (Espanha), p. 100-113, ene. 2010. Disponivel em:

<http://www.estudiosvisuales.net/revista/pdf/ num7/07 sergiomluna.pdf>. Acessado em: 24 abr. 16. MARTINS, Alice Fátima. Catadores de sucata da indústria cultural. Goiânia: Editora da UFG, 2013.

MARTINS, Raimundo. A cultura visual e a construção social da arte, da imagem e das práticas do ver. In: OLIVEIRA de OLIVEIRA, Marilda. (Org.). Arte, educação e cultura. 2. ed. rev. e ampli. Santa Maria: Editora UFSM, 2015. p. 17-38.

MIRZOEFF, Nicholas. The right to look: a counter history of visuality. NC (EUA): Duke University Press, 2011.

MITCHELL, William John Thomas. Não existem mídias visuais. In: DOMINGUES, Diana. (Org.). Arte, ciência e tecnologia: passado, presente e desafios. São Paulo: UNESP, 2009. p. 167-177.

What do pictures want? The Lives and Loves of Images. Chicago (EUA): The University of Chicago Press, 2005.

OLIVEIRA, Paulo Passos de. Entrevista por telefone com Josafá Ferreira Duarte. Goiânia (GO), 02 de maio de 2016a (Não publicada).

Entrevista presencial com Josafá Ferrei-

ra Duarte. Sobral (CE), 23 de agosto de 2013 (Não publicada).
Josafá Duarte e o cinema autodidata. In:

V COLÓQUIO INTERNACIONAL EDUCACIÓN Y VISUALIDAD, 5., 2016b, Montevidéu (Uruguai). Anais... Montevidéu: Universidad de la República: 2016b. (No prelo).

SHUSTERMAN, Richard. Postmodernist aestheticism: a new Moral Philosophy? Theory, Culture \& Society, v. 5, n. 2, p. 337-355, jun. 1988. Disponivel em:

<https:// www.academia.edu/5411618/_Postmodernist_Aestheticism_A_New_Moral_Philosophy_>. Acesso em: 20 dez. 2016.

TURNER, Graeme. Cinema como prática social. São Paulo: Summus Editorial, 1997.

WILLIAMS, Raymond. The long revolution. New York (EUA): Penguin Books, 1965.

\section{Referência eletrônica}

Blog Forquilha Cinecordel. Disponivel em: $<\underline{h t t p}: / /$ cinecordel.blogspot.com.br/p/blog-page.html>.

\section{Referências filmográficas}

A HISTÓRIA de um galo assado. Direção: DUARTE, losafá Ferreira. Forquilha (CE): 2006. 30", VHS, color.

CADÊ meu zóculos? (versão curta-metragem). Direção: DUARTE, Josafá Ferreira. Forquilha (CE): 2015. 20"01, Vídeo, color. Disponivel em: <http://cinecordel.blogspot.com.br/>.

O HOMEM que queria enganar a morte. Direção: DUARTE, Josafá Ferreira. Forquilha (CE): 2014. 46" 22. Vídeo, color. Disponivel em < https://www.youtube. com/watch?V=YSIGSYUcngw>.

POR DEBAIXO dos panos. Direção: DUARTE, Josafá Ferreira. Forquilha (CE): 2010. 1'36"48. Vídeo, color. Disponivel em: <http://cinecordel.blogspot.com. br/2014/07/por-debaixo-dos-panos-ze-das-cachorras.html>.

Recebido em: 30.12.2016

Aprovado em: 15.03.2017 
Paulo Passos de Oliveira é Mestre em Comunicação e Cultura pela Universidade Federal do Rio de Janeiro. Doutorando no Programa de Pós-Graduação em Arte e Cultura Visual da Universidade Federal de Goiás. Grupo de Pesquisa Cultura Visual e Educação (GPCVE) da Universidade Federal de Goiás. Telefone Celular: (62) 98149-9969. e-mail: paulopassosdeoliveira@gmail.com

Raimundo Martins é Professor Titular na Faculdade de Artes Visuais (FAV) da Universidade Federal de Goiás. Coordenador do Programa de Pós-Graduação em Arte e Cultura Visual. Grupo de Pesquisa Cultura Visual e Educação (GPCVE) da Universidade Federal de Goiás. Telefone Celular: (62) 99281-6030. e-mail: martins.raimar@gmail.com

Universidade Federal de Goiás (UFG). Campus Samambaia. Caixa Postal 131 - 74.001-970 - Goiânia (GO) - Brasil. Secretaria: Telefax (62) 3521-1440; - 